\title{
pH Meter
}

\author{
Andrew J. McLean ${ }^{1}$
}

Received: 19 April 2017 / Accepted: 22 June 2017 / Published online: 20 July 2017

(C) Academic Psychiatry 2017

\section{Artist's Statement}

This poem, which refers to a colleague's suicide after struggling with terminal illness, took years to write. Emotions of guilt, anger, and doubt were only a few of the elements contributing to the delay. We have the obvious need for eliminating barriers that prevent individuals (practitioners in particular) from reaching out for help. However, when approaching a topic such as this, we must also keep in mind what Gillon referred to as "attention to scope" [1]. Despite the continued relevance of beneficence, non-maleficence, and justice within Beauchamp and Childress's four principles model of medical ethics [2], it can be argued that "autonomy" is paramount in patient-centered medicine and end of life matters. I believe there could have been a more caring, comforting, and respectful venue and choice for my colleague's final act. It is hoped that this poem will contribute to professional and societal discourse on the issue.
Andrew J. McLean

andrew.mclean@med.und.edu

1 UND School of Medicine and Health Sciences, Fargo, ND, USA
$\mathrm{pH}$ Meter

Among life's

acids and bases, you,

my physician colleague

could not find

balance; a solution

other than isolation,

suffering in silence

and dying by your own hand

alone in a field.

Imagine

A litmus test

Of soothing, neutralizing balm

To counter the

Unbuffered salts in this

Wound of life.

Relief-

From the burden of:

Hidden fears and wishes;

Protracted discomfort;

Medical futility;

Sanctimonious tripe.

Imagine.

Societal chemistry-

A dialogue of choice including

Non-violent departure

Discussed and supported;

Surrounded by friends and family.

Imagine.

\section{References}

1. Gillon R. Medical ethics: four principles plus attention to scope. BMJ. 1994;309:184.

2. Beauchamp T, Childress J. Principles of biomedical ethics. 7th ed. Oxford: Oxford University Press; 2012. 